\title{
A RARE CASE OF ACCESSORY METATARSAL WITHOUT POLYDACTYLY A CASE REPORT WITH REVIEW OF LITERATURE
}

Rapaka Radhakrishna1, Bandrapalli Ravi Babu²

\section{HOW TO CITE THIS ARTICLE:}

Rapaka Radhakrishna, Bandrapalli Ravi Babu. "A Rare Case of Accessory Metatarsal without Polydactyly a Case Report with review of Literature". Journal of Evolution of Medical and Dental Sciences 2015; Vol. 4, Issue 67, August 20; Page: 11780-11784, DOI: 10.14260/jemds/2015/1699

ABSTRACT: Accessory metatarsal without polydactyly is a very rare presentation and we present a very rare case of bilateral accessory metatarsal without polydactyly. No other congenital anomalies were noted.

KEYWORDS: Accessory metarsal, Polydactyly.

INTRODUCTION: Accessory metatarsal with polydactyly is common. ${ }^{1}$ but accessory metatarsal without polydactyly is very rare and very few cases were reported. We present this rare case of accessory fourth metatarsal without polydactyly with the opinion that plantar approach is better and suturing in a single layer with monofilament suture has better results.

CASE REPORT: A4 year old girl presented with difficulty in walking due to pain in right foot since 1 year, with history of frequent falls. She has no complaints in her left foot.

No other significant history.

On examination there was a swelling on the plantar aspect of right foot, local tenderness present over the swelling with no signs of inflammation. On palpation the swelling was hard in consistency, not mobile. The ankle joint and subtalar movements were normal, no other joints were involved . Toes of both feet were normal.

We have taken plain radiograph of both feet which showed accessory metatarsal which was at $4^{\text {th }}$ metatarsal without polydactyly. CT scan of both feet was also done to confirm our diagnosis.

Excision of the accessory metatarsal was done through plantar incision and wound closed in single layer with 4-0 monofilament non-absorbable suture. On follow up child had painfree walking

DISCUSSION: Polydactyly is a congenital anamoly where there are extra digits on hands, feet or both. ${ }^{2}$ this condition may be associated with duplication of metatarsals or metacarpals. It is called as polymetatarsia if it involves fore-foot. Accessory metatarsal with polydactyly is very common, but accessory metatarsal without polydactyly is very rare and very few cases have been reported.3,4,5

In earlier references, occurance of accessory metatarsal was common between $4^{\text {th }}$ and $5^{\text {th }}$ metatarsal and attached to $5^{\text {th }}$ metatarsal, in our case it was not only bilateral but was attached to $4^{\text {th }}$ metatarsal.

Further reference suggested superiority of plantar approach compared to dorsal approach which carried the morbidity such as hammer toe deformity, metatarsophalangeal joint contracture, transverse plane MIJ deformities, hematoma, and vascular insults to digits. We are reporting this case because of its rarity and with the suggestion that plantar approach is superior ${ }^{6}$ if swelling is prominent over plantar aspect. 


\section{CASE REPORT}
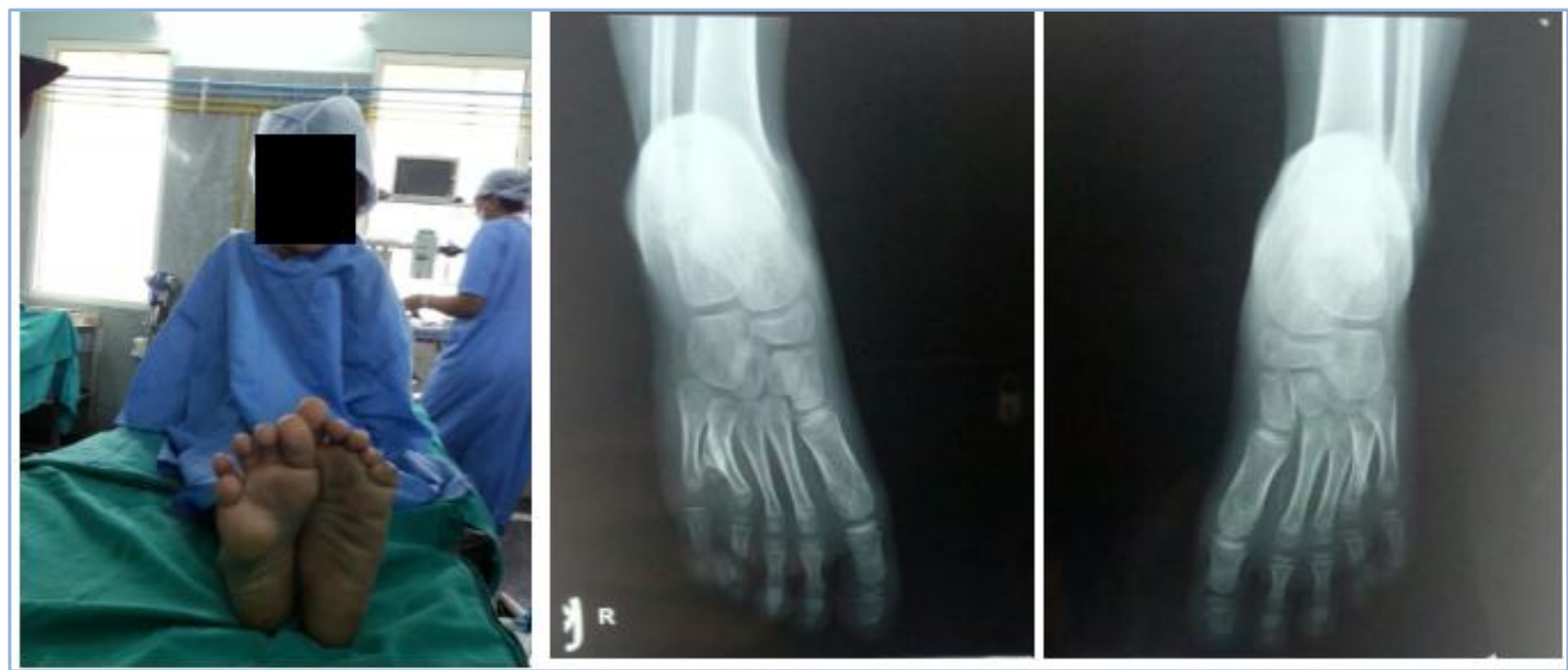

Pre-operative- clinical

$$
\text { X-RAY } 1
$$

X-RAY 2

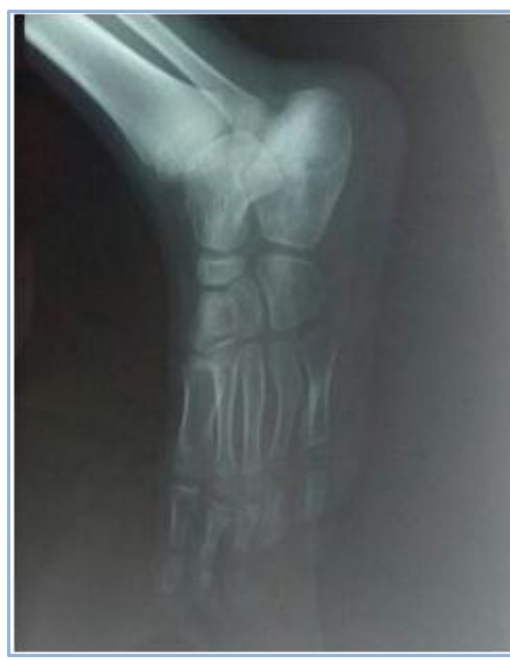

X-RAY 3

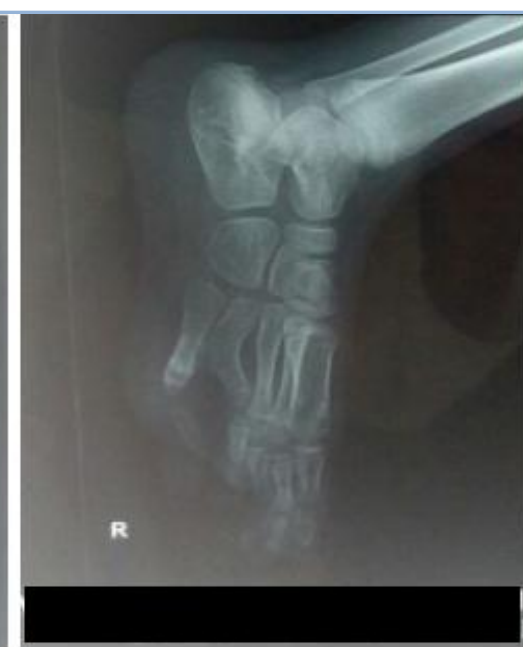

X-RAY 4

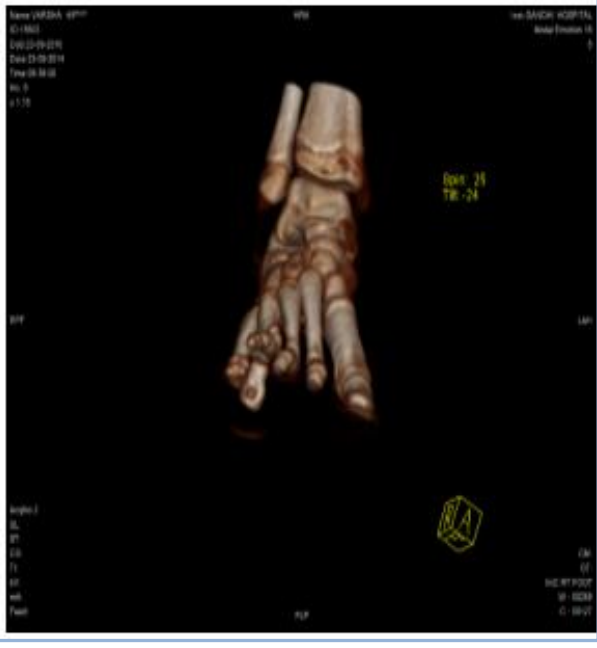

3D CT 1

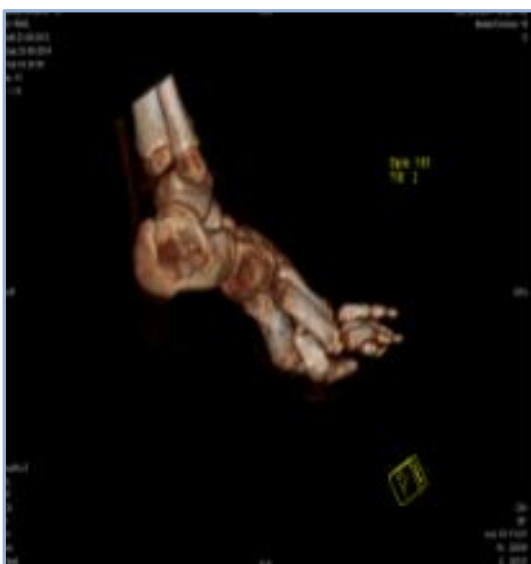

3D CT2

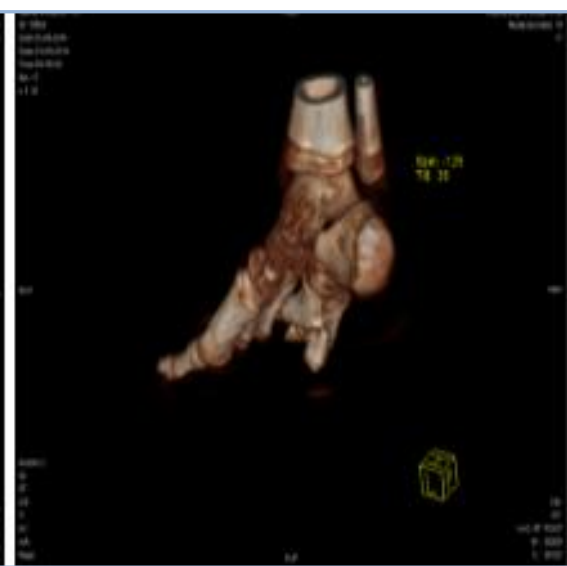

3D CT 3

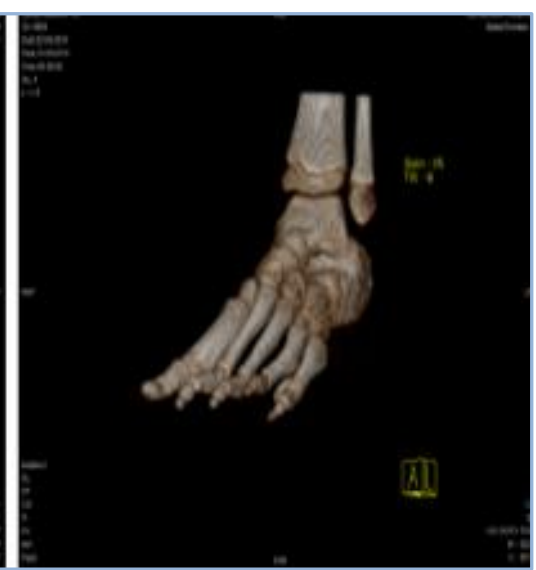

3D CT4 


\section{CASE REPORT}

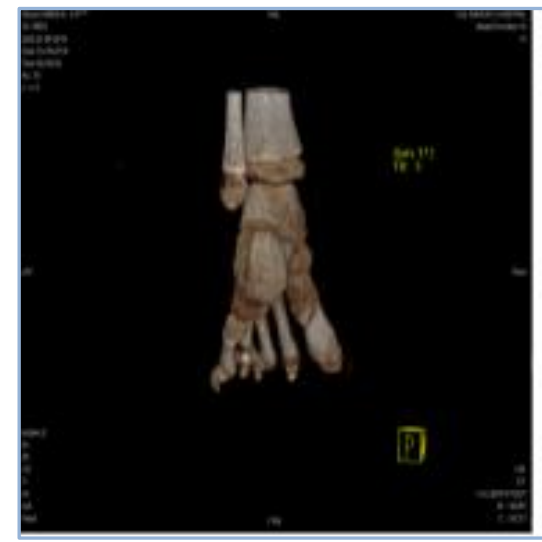

3D CT 5

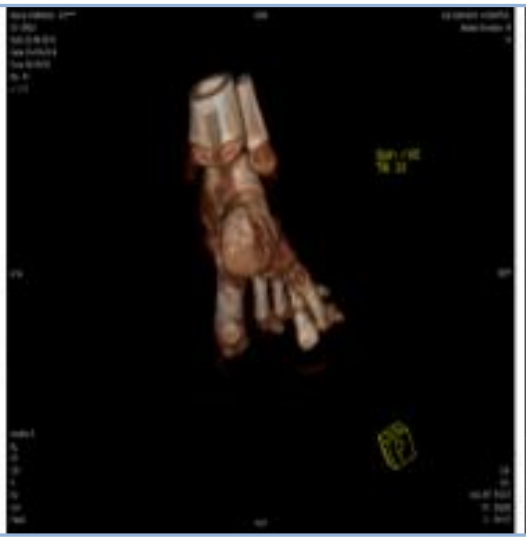

3D CT6

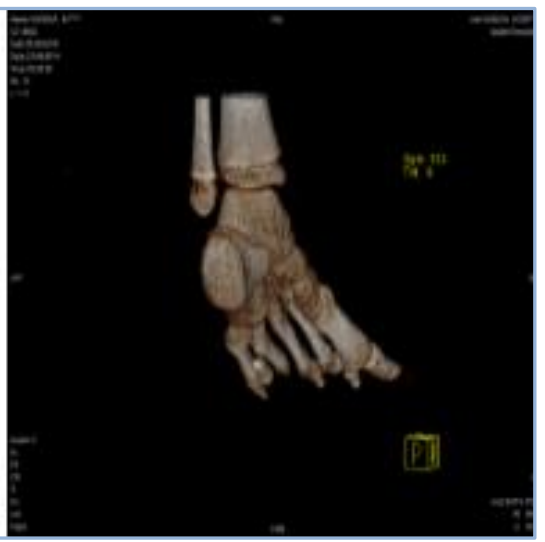

3D CT 7

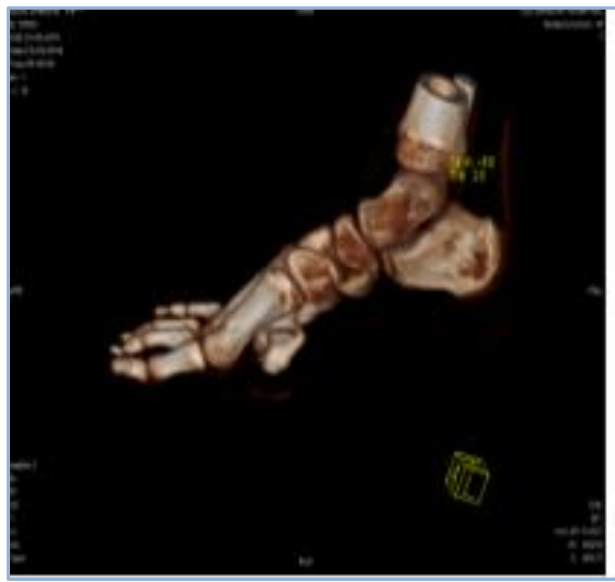

3D CT 8

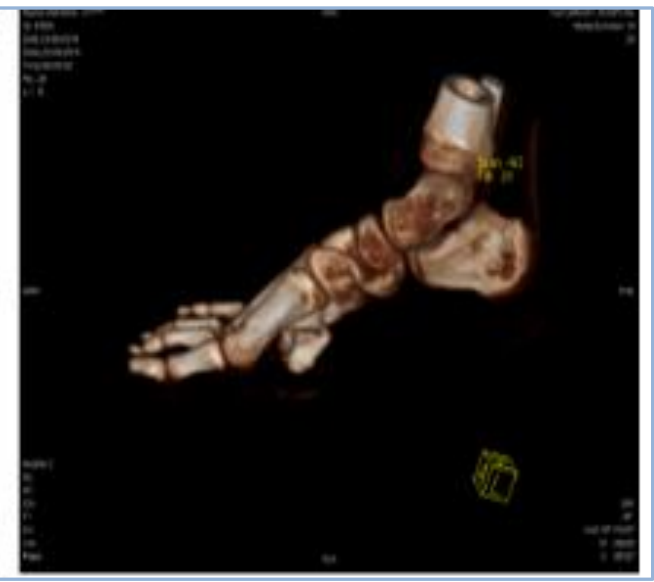

3D CT9
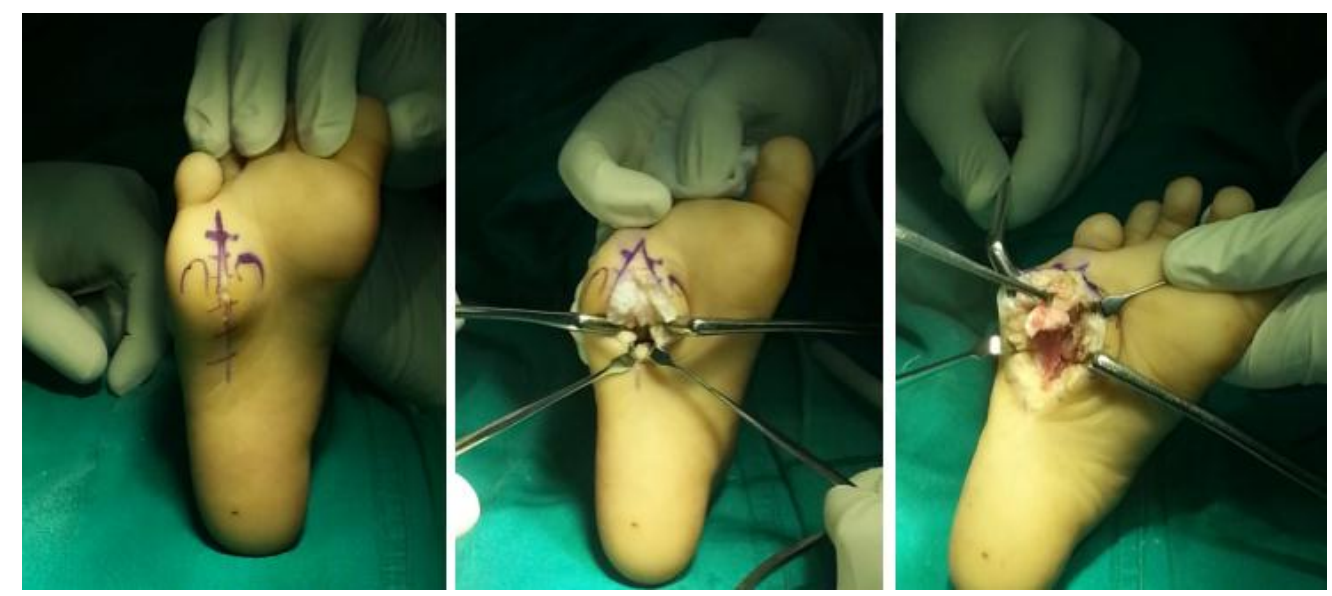

Intraoperative -plantar approach 


\section{CASE REPORT}
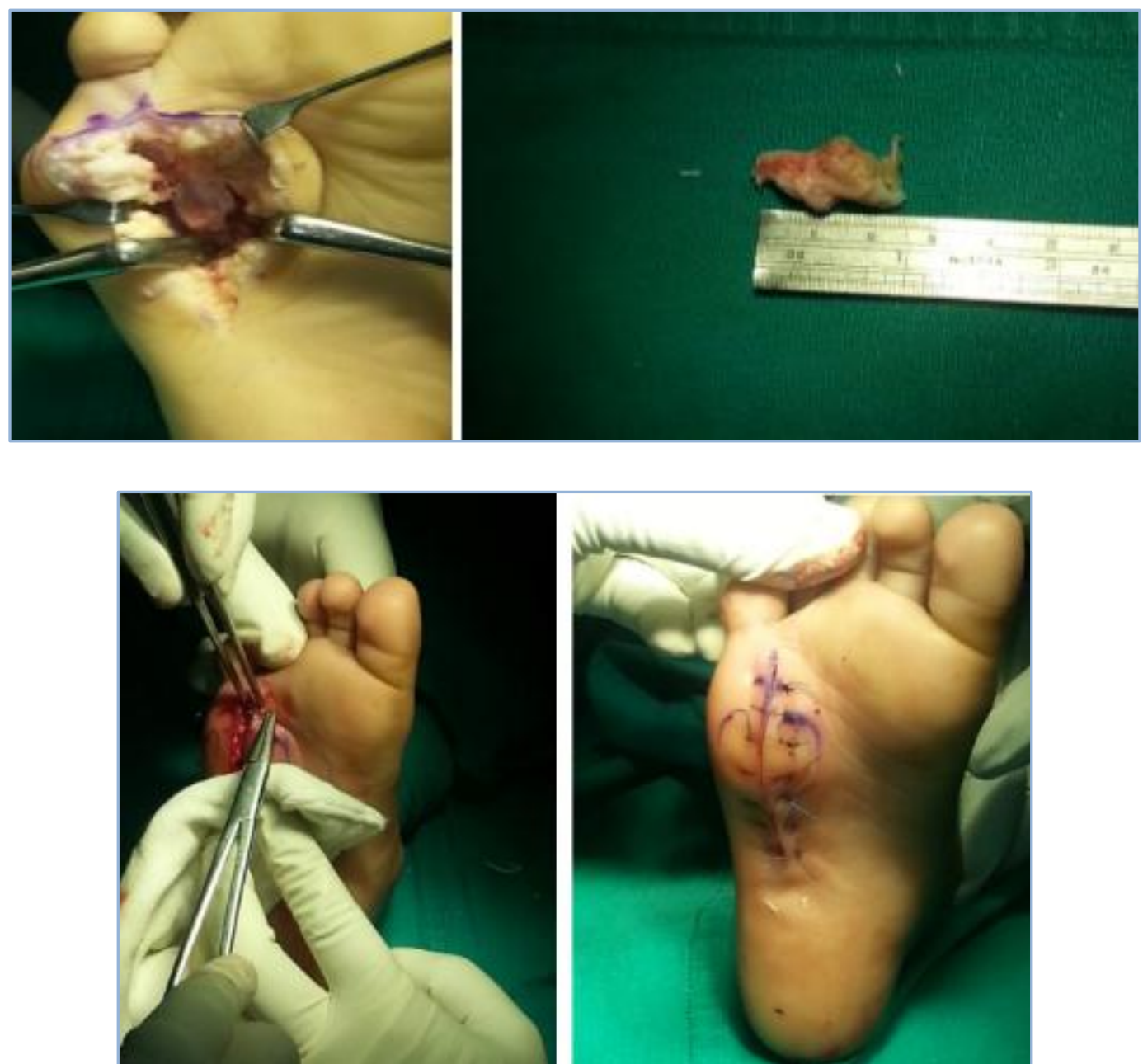

Sutured in single layer with monofilament 4-0 suture

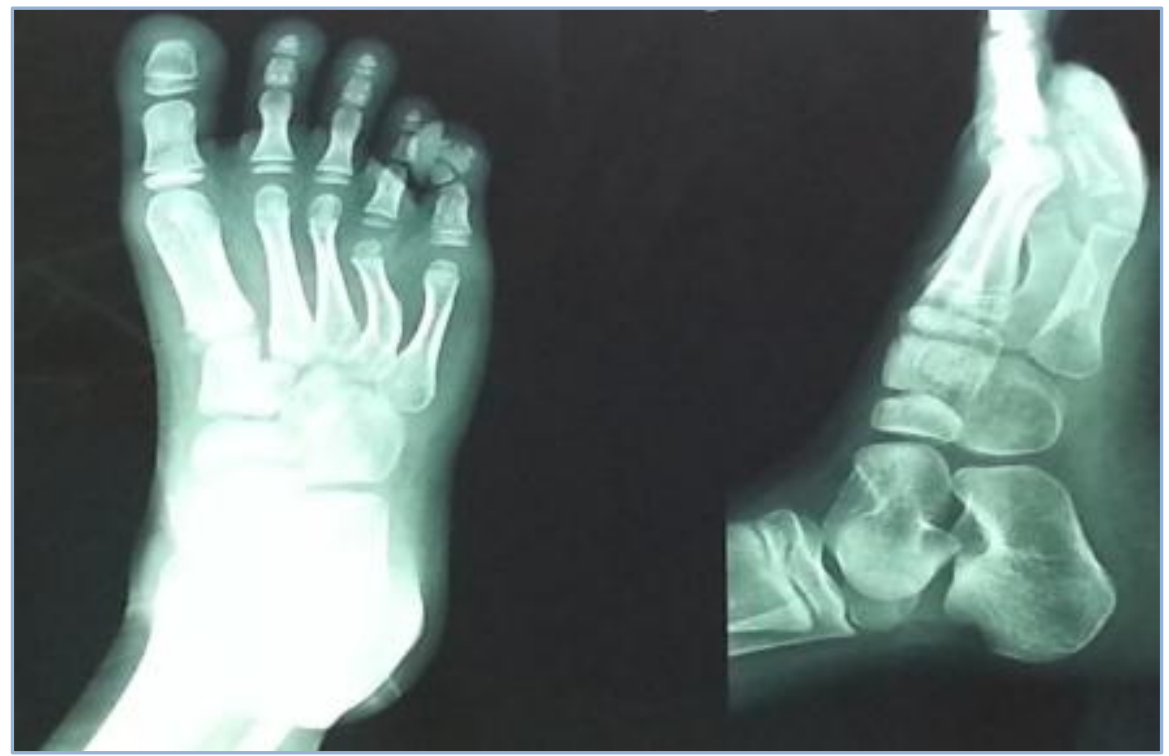

Post-operative $\mathrm{x}$-rays 


\section{CASE REPORT}

\section{REFERENCES:}

1. Polydactyly of the foot: Literature review and case presentations-By L.Galois et al, Acta Orthopaedics Belgica, Vol.68-4-2002.

2. Classification of Postaxial polydactyly of foot by Lee et al Foot Ankle Int, 2006 May; 27(5):35662.

3. Ishi et al in Br.J Plast Surg.2005 Mar; 58(2):267-70.

4. Masahiko Nozawa et al- Bizarre accessory metatarsal located between the left fourth and fifth metatarsals 3. In "The Foot 19(2009)130-132.

5. Jaime Gomez Robledo in the Foot and Ankle online journal 8(1):2, 2015.

6. Chapter 3: Plantar incision for excision of intermetatarsal neuroma-By A. Louis Jimenez, DPM, update 2002 of podiatryinstitute.com.

\section{AUTHORS:}

1. Rapaka Radhakrishna

2. Bandrapalli Ravi Babu

\section{PARTICULARS OF CONTRIBUTORS:}

1. Assistant Professor, Department of Orthopaedics, Gandhi Medical College and Gandhi Hospital, Hyderabad.

2. Professor \& HOD, Department of Orthopaedics, Gandhi Medical College and Gandhi Hospital, Hyderabad.

FINANCIAL OR OTHER COMPETING INTERESTS: None
NAME ADDRESS EMAIL ID OF THE CORRESPONDING AUTHOR:

Dr. Rapaka Radhakrishna, Assistant Professor of Orthopaedics, 3-7-62/371, Southend Park, GSI Post, Mansurabad, Hyderabad-500068, Telangana.

E-mail: drrapaka@yahoo.com

Date of Submission: 03/08/2015.

Date of Peer Review: 04/08/2015.

Date of Acceptance: 17/08/2015.

Date of Publishing: 20/08/2015. 